\title{
Optimization of the EDM Parameters on the Surface Roughness of DIN 1.2767 Tool Steel Using Taguchi Method
}

\author{
Abubaker Yousef Fatatit ${ }^{1}$ and Ali Kalyon ${ }^{2 *}$ \\ ${ }^{1}$ Karabük University, Natural and Applied Sciences, 078050 Karabük, Turkey \\ ${ }^{2}$ Yalova University, Engineering Faculty, Mechanical Eng. Dep. 077200 Yalova, Turkey
}

\begin{abstract}
.
Manufacturing processes affect surface properties, as a result, they significantly affect the component lifetime. In Electric Discharge Machining (EDM), the component surface is subject to high localized thermal energy that produces changes in surface quality such as surface hardness, roughness, surface crack density and white layer thickness. In the present paper, Taguchi method and ANOVA has been implemented to obtain the optimal EDM process parameters affecting on DIN 1.2767 tool steel surface. The process parameters were electrode materials (B2, NSS), discharge current (6, 12 and 25 A), pulse on time (50, 200 and $800 \mu \mathrm{s})$ and pulse off time $(50,200$ and $800 \mu \mathrm{s})$. From the results, it was found that the discharge current has the highest influence on surface roughness followed by pulse on time and the influence of electrode material and pulse off time were insignificant. The optimal surface finish can be achieved at low discharge current and long pulse on time and pulse off time and utilize B2 electrode. Scanning Electron Microscopy (SEM) images revealed the alterations in the surface roughness and surface crack density.
\end{abstract}

Keywords: EDM, Taguchi, steel, NSS, B2, Surface roughness

\section{Introduction}

EDM is among the unconventional manufacturing techniques that have a major role in the manufacture of complex geometrical shapes and mechanical properties that are difficult to machine in conventional methods (Ho \& Newman, 2003). Also, the achievement of accurate dimensions and improvement in the surface finishing of hard materials and advanced engineering materials greatly contributed to the spread of this technology (Selvarjan, Manohar, Jayachandran, Mouri, \& Selvakumar, 2018). EDM application seems to be flourishing swiftly for the manufacture of moulds, punches and dies. Those have wellestablished application in manufacturing of components of aerospace, automotive, surgical, marine, nuclear, and petroleum (Mahajan, Sidhu, \& Devgan, 2020). Electric discharge machining removes metal by a series of rapidly repetitive electrical discharges (sparks) between the tool and the workpiece submerged in a dielectric fluid. Each spark causes localized temperatures high enough to melt or vaporize a small amount of material. A large number of sparks occur in a very short time creating melted pool that partially ejected in a form of liquid globules and not ejected molten metal is re-solidified and leaves a tiny hemispherical crater which produces and forms the surface textures and affecting surface integrity (Black \& Kohser, 2012; Groover, 2010; Guitrau, 1997). The volume of melted 
material based on the discharge energy. As a result of the discharge energy increases, the surface roughness and the recast layer increase (Boujelbene, Bayraktar, \& Wissem, 2009).

Several previous studies were interested in studying the effect of the input factors on the responses to achieve the best performance of the EDM by conducting practical experiments, analyzing the results, and using mathematical and statistical methods. (Arunkumar, Rawoof, \& Vivek, 2012) investigated the effect of process parameters on the performance of EN31(air hardened steel) based on Taguchi Orthogonal Array (OA). The results show that the Ra is influenced by electrode material, flushing pressure, Ip and Ton. In addition, the variation in $\mathrm{Ra}$ varies erratically for all electrodes (copper, aluminum and EN-24) but the minimum variation produced by copper electrode. Also, it was found that the minimum Ra can be achieved at low values of Ip. (Janardhanan et al., 2016) studied the effect of EDM process parameters on SR in Inconel 825 Alloy, applied $\mathrm{L}_{16}$ OA based in Taguchi to design the experiments and optimize the process parameters and ANOVA to identify the contribution of each parameter. The results revealed that Ip has the highest contribution $82.31 \%$ followed by Ton $13.51 \%$ and Toff $0.89 \%$. (Chandramouli \& Eswaraiah, 2018) applied L 27 Taguchi method to determine the influence of process parameters and optimization of 17-4 PH steel in EDM, and copper tungsten electrode was used. The machining parameters are Ip $(9,12,15 \mathrm{~A})$, Ton $(50,100,200 \mu \mathrm{s})$, Toff $(20,50,100 \mu \mathrm{s})$, and lift time $(10,20,50 \mu \mathrm{s})$. Results showed that the Ip and Ton have significant influence on surface roughness (SR) while Toff has a lower

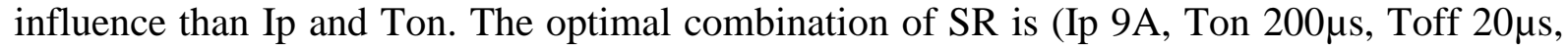
and lift time $10 \mu \mathrm{s})$. The highest percentage contribution of the parameters is Ton $(83.55 \%)$ followed by Ip $(7.5 \%)$, lift time $(0.75 \%)$ and the least Toff $(0.507 \%)$. There is slight interaction effect between parameters for SR. (Sanjeev Sharma, Rajdeep Singh, \& Sandeep Jindal, 2015) studied the influence of machining parameters in EDM of EN 31 Die Steel. Taguchi method and ANOVA were applied to optimize the machining parameters. The parameters ware Ip $(10,15,20 \mathrm{~A})$, Ton $(30,60,90 \mu \mathrm{s})$ and Toff $(15,30,45 \mu \mathrm{s})$. The results revealed that Ip is the most significant factors effects on Ra with a contribution of $74.30 \%$ followed by Ton $12.67 \%$ and Toff $6.30 \%$. Optimum combination of parameters which

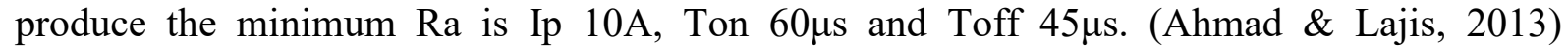
experimentally investigated Inconel 718 at higher peak current $(20,30,40 \mathrm{~A})$ and pulse duration $(200,300,400 \mu \mathrm{s})$ and concluded that the minimum surface roughness (Ra) achieved at low value of peak current and short pulse-on time. (Patil \& Jadhav, 2016) studied the machining parameters in EDM and observed that the SR increases with increase of Ip and Toff, whereas long Ton reduces the SR. (Jamwal, Vates, \& Aggarwal, 2017) reviewed papers and observed that the higher intensity of the spark produces the higher material removal rate but it affects the surface quality. SR increases with the higher values of Ip. It is also found in the study that higher values of Toff increase the surface quality.

Hamid \& Lajis, 2012 experimentally investigated the machining performance in EDM machining of AISI D2 hardened steel. The process parameters Ip (20, 32, 40A) and Ton (400, $500,600 \mu \mathrm{s})$. The results revealed that the lowest surface roughness obtained at the lowest Ip and longest Ton.(Habib, 2014) optimized machining parameters of DIN 2714 hot work tool steel using Taguchi method. The machining parameters for copper electrode are Ip $(1,4,6 \mathrm{~A})$, Ton $(50,100,150 \mu \mathrm{s})$, Toff $(40,50,60 \mu \mathrm{s})$ and the $\mathrm{V}(40,50,60)$. It is reported that Ton is the most significant factor affecting SR with contribution $86.33 \%$ followed by Ip $7.51 \%$ then Toff 4.7\%. High Ip and long Ton produce deeper and wider craters on the EDM machined surface. (Mahajan et al., 2020) studied the performance of different copper and copper-based 
electrodes used in EDM process and mentioned that at utilizing a copper electrode and brass electrode SR is comparatively high at higher values of discharge current. (Guu, 2005) revealed that a higher discharge energy causes a poorer surface quality. To avoid excessive machined damage, low Ip and short Ton should be used. In this present study, the DIN 1.2767 tool steel was EDM machined with two copper-based electrodes to obtain the optimal process parameters for minimum SR applying Taguchi $\mathrm{L}_{18} \mathrm{OA}$. In this study, Taguchi method and ANOVA has been implemented to obtain the optimal EDM process parameters affecting on DIN 1.2767 tool steel surface. The process parameters were electrode materials (B2, NSS), discharge current $(6,12$ and $25 \mathrm{~A})$, pulse on time $(50,200$ and $800 \mu \mathrm{s})$ and pulse off time (50, 200 and $800 \mu \mathrm{s})$.

\section{Experimental work and methodology}

\subsection{Materials and experimental setup}

Tool steel DIN 2767 (45NiCrMo16) was utilized as a workpiece. This material has wide application in the industry for example cutting tools, cutlery punches, bending tools, embossing tools, cold hobbing tools, pressure bars, cold shear knives, plastic moulds, billet shear knives hot press tools, drawing jaws due to its good mechanical properties such as high toughness, good through-hardenability, high impact strength and pressure resistance. The chemical composition of DIN 2767 is shown in Table 1. The size of each workpiece is 50mm $X 25 \mathrm{~mm} X 12 \mathrm{~mm}$, the surface was milled and finish ground before performing the EDM experiments. The initial surface roughness slightly affecting workpiece surface roughness after EDM machining (Hadad, Bui, \& Nguyen, 2018). However, kerosene was used in experiments as a dielectric and copper alloys as electrodes. Kerosene and copper electrodes are currently at peak use in EDM (Vishwakarma, Yadav, Kumar, \& Krishhna, 2017). Two different electrodes-based copper - namely, NSS and B2 - with $15 \mathrm{~mm}$ diameter and $100 \mathrm{~mm}$ height were used to machine the workpieces. These electrodes have physical properties that are suitable for use in EDM. Electrodes physical properties such as thermal conductivity, melting point and electrical resistivity (or electric conductivity) would affect the roughness value of the surface (Fikri, Romlie, \& Aminnudin, 2017). Table 2 presents the chemical properties of the electrodes and Tables 3 and 4 present their chemical properties. Before performing experiments, surfaces of electrodes are prepared by polishing on silicon carbide paper with different grit sizes in this sequence, 150, 240, 320, 400, 600 and 800. The experiments were carried out on the FURKAN M25A sinker electrical discharge machine with lateral flushing. The lateral flushing is constant at pressure 0.25 bar. The tool electrode was the negative polarity and the workpiece was the positive polarity during the EDM process. The optimal SR was determined for copper tool electrodes under negative polarity (Amorim \& Weingaertner, 2007).

Table 1 Chemical composition (wt \%) of DIN 1.2767

\begin{tabular}{|l|l|l|l|l|l|l|l|}
\hline Element & $\mathrm{C}$ & $\mathrm{Si}$ & $\mathrm{Mn}$ & $\mathrm{Cr}$ & $\mathrm{Mo}$ & $\mathrm{Ni}$ & $\mathrm{Fe}$ \\
\hline Weight $(\%)$ & 0.45 & 0.25 & 0.35 & 1.35 & 0.25 & 4.05 & Balance \\
\hline
\end{tabular}

Table 2 Chemical Composition: Nss (CuNi2SiCr)

\begin{tabular}{|l|l|l|l|l|l|l|l|}
\hline Element & $\mathrm{Si}$ & $\mathrm{Mn}$ & $\mathrm{Cr}$ & $\mathrm{Ni}$ & $\mathrm{Fe}$ & $\mathrm{Pb}$ & $\mathrm{Cu}$ \\
\hline Weight $(\%)$ & 0,65 & 0,10 & 0,35 & 2,5 & 0,15 & 0,02 & Balance \\
\hline
\end{tabular}


Table 3 Chemical Composition B2 ( $\mathrm{CuBe2})$

\begin{tabular}{|l|l|l|l|l|l|}
\hline Element & $\mathrm{Ni}$ & $\mathrm{Be}$ & $\mathrm{Co}$ & $\mathrm{Fe}$ & $\mathrm{Cu}$ \\
\hline Weight (\%) & 0,30 & 1,95 & 0,30 & 0,20 & Balance \\
\hline
\end{tabular}

Table 4 Physical properties of the electrodes

\begin{tabular}{|l|l|l|l|l|}
\hline & $\begin{array}{l}\text { Density } \\
\mathrm{g} / \mathrm{cm}^{3}\end{array}$ & $\begin{array}{c}\text { Electrical conductivity } \\
\mathrm{MS} / \mathrm{m}\end{array}$ & $\begin{array}{l}\text { Thermal conductivity } \\
\mathrm{W} / \mathrm{m} \mathrm{K}\end{array}$ & $\begin{array}{c}\text { Melting } \\
\text { temperature range }\end{array}$ \\
\hline B2 & 8.3 & $\geq 16$ & $120-170$ & $870-980$ \\
\hline NSS & 8.81 & $\geq 23$ & $190-240$ & $1020-1040$ \\
\hline
\end{tabular}

\subsection{Materials and experimental setup}

At the selection of machining parameters and their levels, the machinability and previous studies were considered. The process parameters and levels are listed in the Table 5.

Table 5 Control Factors and levels

\begin{tabular}{|l|l|l|l|l|}
\hline Factor & Unit & Level 1 & Level 2 & Level 3 \\
\hline Tool Material & & B2 & NSS & \\
\hline Ip & A & 6 & 12 & 25 \\
\hline $\mathrm{T}_{\text {on }}$ & $\mu \mathrm{S}$ & 50 & 200 & 800 \\
\hline $\mathrm{T}_{\text {off }}$ & $\mu \mathrm{s}$ & 50 & 200 & 800 \\
\hline
\end{tabular}

Experiments were planned and conducted according to the Taguchi`s L18 OA. Taguchi optimization technique is widely applied in optimizing process parameters of EDM (Sanghani \& Acharya, 2014). Taguchi has presented a combined measure focus on identifying factors that affect mean response and detect factors that affect variability of the response. Optimization in Taguchi technique means identifying the best levels of control factors that minimize the variance. In Taguchi's technique signal to noise ratio ( $\mathrm{S} / \mathrm{N}$ ratio) is implemented to determine the effect of input factors on the output. The $\mathrm{S} / \mathrm{N}$ ratio is a combined measure of mean and variance (Krishnaiah \& Shahabudeen, 2012). Computing S/N ratio based on the condition of optimization. The best levels of process parameters are those that maximize the $\mathrm{S} / \mathrm{N}$ ratio. For surface roughness, minimum surface roughness is preferable, in $\mathrm{S} / \mathrm{N}$ ratio "smaller-is-better" that denotes by Equation 1.

$S / N=-10 \log \left[\frac{1}{n} \sum_{i=1}^{n} y_{i}^{2}\right]$

\subsection{Surface roughness $(\mathrm{SR})$}

In EDM, the surface of the workpiece is subjected to electric sparks, which contribute to form a tiny crater. These craters create the surface roughness of the workpiece. Surface roughness is an important performance measure that affected by EDM machining factors since it affects mechanical properties of the workpiece such as fatigue strength and wear resistance. There are many different roughness parameters in use such as Arithmetic mean value of roughness $(\mathrm{Ra})$, the mean square root value $(\mathrm{Rq})$ and Mean Roughness Depth $(\mathrm{Rz})$. Three distinct measurements were taken at different locations using Mitutoyo digital surface roughness tester as shown in Figure 1. and the average surface roughness was calculated. 
Fig. 1. Measuring surface roughness of EDMed workpieces

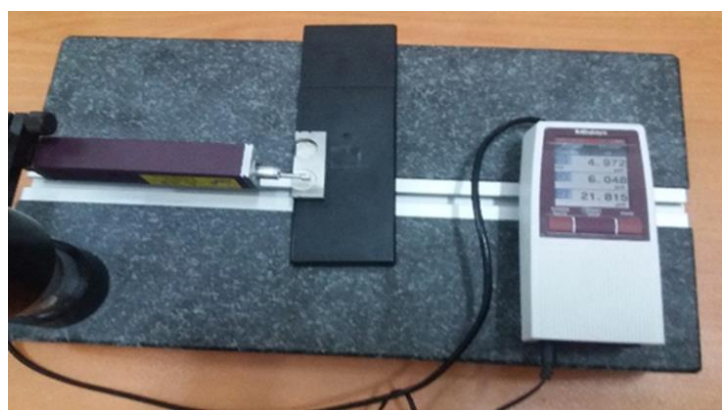

\section{Result and discussion}

As can be seen from Table 6 , the minimum surface roughness $(1.618 \mu \mathrm{m})$ was obtained at combination of parameters E1A1B3C3 and the maximum surface roughness $(10.88 \mu)$ at $\mathrm{E} 1 \mathrm{~A} 3 \mathrm{~B} 3 \mathrm{C} 2$. We note from the table also that when machining with the parameters A1B3C3 for both electrodes, the lowest value for the surface roughness can be achieved.

Table 6 Experimental results

\begin{tabular}{|l|l|l|l|l|l|l|}
\hline Sq. & Control factors & Tool & Ip & $\mathrm{T}_{\text {on }}$ & $\mathrm{T}_{\text {off }}$ & Ra \\
\hline 1 & $\mathrm{E}_{1} \mathrm{~A}_{1} \mathrm{~B}_{1} \mathrm{C}_{1}$ & $\mathrm{~B} 2$ & 6 & 50 & 50 & 3.846 \\
\hline 2 & $\mathrm{E}_{1} \mathrm{~A}_{1} \mathrm{~B}_{2} \mathrm{C}_{2}$ & $\mathrm{~B} 2$ & 6 & 200 & 200 & 2.801 \\
\hline 3 & $\mathrm{E}_{1} \mathrm{~A}_{1} \mathrm{~B}_{3} \mathrm{C}_{3}$ & $\mathrm{~B} 2$ & 6 & 800 & 800 & 1.618 \\
\hline 4 & $\mathrm{E}_{1} \mathrm{~A}_{2} \mathrm{~B}_{1} \mathrm{C}_{2}$ & $\mathrm{~B} 2$ & 12 & 50 & 200 & 4.745 \\
\hline 5 & $\mathrm{E}_{1} \mathrm{~A}_{2} \mathrm{~B}_{2} \mathrm{C}_{3}$ & $\mathrm{~B} 2$ & 12 & 200 & 800 & 7.557 \\
\hline 6 & $\mathrm{E}_{1} \mathrm{~A}_{2} \mathrm{~B}_{3} \mathrm{C}_{1}$ & $\mathrm{~B} 2$ & 12 & 800 & 50 & 2.422 \\
\hline 7 & $\mathrm{E}_{1} \mathrm{~A}_{3} \mathrm{~B}_{1} \mathrm{C}_{3}$ & $\mathrm{~B} 2$ & 25 & 50 & 800 & 5.785 \\
\hline 8 & $\mathrm{E}_{1} \mathrm{~A}_{3} \mathrm{~B}_{2} \mathrm{C}_{1}$ & $\mathrm{~B} 2$ & 25 & 200 & 50 & 9.199 \\
\hline 9 & $\mathrm{E}_{1} \mathrm{~A}_{3} \mathrm{~B}_{3} \mathrm{C}_{2}$ & $\mathrm{~B} 2$ & 25 & 800 & 200 & 10.888 \\
\hline 10 & $\mathrm{E}_{2} \mathrm{~A}_{1} \mathrm{~B}_{1} \mathrm{C}_{1}$ & NSS & 6 & 50 & 50 & 5.791 \\
\hline 11 & $\mathrm{E}_{2} \mathrm{~A}_{1} \mathrm{~B}_{2} \mathrm{C}_{2}$ & NSS & 6 & 200 & 200 & 4.025 \\
\hline 12 & $\mathrm{E}_{2} \mathrm{~A}_{1} \mathrm{~B}_{3} \mathrm{C}_{3}$ & NSS & 6 & 800 & 800 & 2.723 \\
\hline 13 & $\mathrm{E}_{2} \mathrm{~A}_{2} \mathrm{~B}_{1} \mathrm{C}_{2}$ & NSS & 12 & 50 & 200 & 5.349 \\
\hline 14 & $\mathrm{E}_{2} \mathrm{~A}_{2} \mathrm{~B}_{2} \mathrm{C}_{3}$ & NSS & 12 & 200 & 800 & 8.694 \\
\hline 15 & $\mathrm{E}_{2} \mathrm{~A}_{2} \mathrm{~B}_{3} \mathrm{C}_{1}$ & NSS & 12 & 800 & 50 & 4.132 \\
\hline 16 & $\mathrm{E}_{2} \mathrm{~A}_{3} \mathrm{~B}_{1} \mathrm{C}_{3}$ & NSS & 25 & 50 & 800 & 6.095 \\
\hline 17 & $\mathrm{E}_{2} \mathrm{~A}_{3} \mathrm{~B}_{2} \mathrm{C}_{1}$ & NSS & 25 & 200 & 50 & 10.224 \\
\hline 18 & $\mathrm{E}_{2} \mathrm{~A}_{3} \mathrm{~B}_{3} \mathrm{C}_{2}$ & NSS & 25 & 800 & 200 & 10.608 \\
\hline
\end{tabular}

Figure 2 depicts the main effect plot on Ra. The optimal surface finishes achieved at process parameters E1A1B3C3, which can be obtained by maximum values of the mean of $\mathrm{S} / \mathrm{N}$ ratio. The SR value is minimum if the value of Ip at the lower level and Ton and Tof at high levels. From Figure 2. and Table 7, it is clear that Ip is the most effecting process parameter and playing as main factor for minimizing $\mathrm{Ra}$ tracked by Ton then electrode material and the least was Toff. Ra increases sharply as a result of the increase of Ip. The surface roughness increases due to increase discharge energy (Kalyon, 2020). In addition, it is observed that $\mathrm{Ra}$ increases initially, when Ton increases from $50 \mu \mathrm{s}$ to $200 \mu \mathrm{s}$, while tends to decrease, when Ton increases from $200 \mu$ s to $800 \mu$ s. However, the trend of Toff is similar to Ton, where Ra increases when Toff increases from $50 \mu$ s to $200 \mu$ s and tend to decrease when 
Toff increases from $200 \mu$ s to $800 \mu \mathrm{s}$. An excessive Ton creates an expansion of the electric plasma channel, which results in a reduction in both the SR and the MRR (Lee, Hsu, \& Tai, 2004).

Fig. 2. Signal-to-noise graph for surface roughness

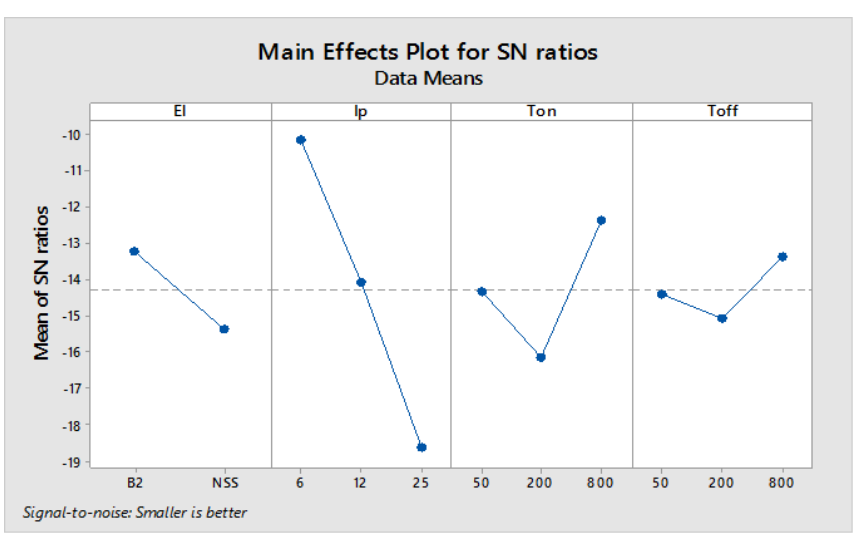

Figure 3 illustrates six interaction plots for various two-parameters interactions between electrode material, Ip, Ton and Toff. In the interaction plot if the lines are parallel, the interaction effect does not exist. The strength of the degree of interaction is distinguished by the degree of non-parallelism between the lines (Krishnaiah \& Shahabudeen, 2012). It is observed that, no interaction effect between electrode material and other parameters, and this may be caused by the convergence of the physical properties. While there are strong interactions between other parameters (Ip, Ton, Toff) which is obvious that the significant change on the surface roughness as a result of the effect of one parameter depends on the level of the other parameters. This clears the complex relationship between the parameters and their combined effect on the responses.

Fig. 3. Interaction plot for Ra




Table 7 S/N response table for $S R$

\begin{tabular}{|l|l|l|l|l|}
\hline Level & Electrode & $\mathrm{Ip}$ & $\mathrm{T}_{\text {on }}$ & $\mathrm{T}_{\text {off }}$ \\
\hline 1 & -13.21 & -10.15 & -14.33 & -14.40 \\
\hline 2 & -15.35 & -14.07 & -16.14 & -15.06 \\
\hline 3 & & -18.61 & -12.36 & 1.07 \\
\hline Delta & 2.14 & 8.46 & 3.79 & 1.70 \\
\hline Rank & 3 & 1 & 2 & 4 \\
\hline
\end{tabular}

Figures 4 and 5 show effect of Ton and Toff on the surface roughness and surface crack density. Where it is noticed in the case of process parameters E2A1B1C1 that the surface roughness is higher but the cracks are less compared to the second case when the Ton and Toff increased as in process parameters E2A1B2C2. Also as shown in Figure 5. at machining with process parameters $\mathrm{E} 2 \mathrm{~A} 1 \mathrm{~B} 1 \mathrm{C} 1$ the Ra was $5.791 \mu$ whereas the process parameters $\mathrm{E} 2 \mathrm{~A} 1 \mathrm{~B} 2 \mathrm{C} 2$ the Ra was $4.025 \mu$.

Fig 4. SEM Micrograph at process parameters E2A1B1C1

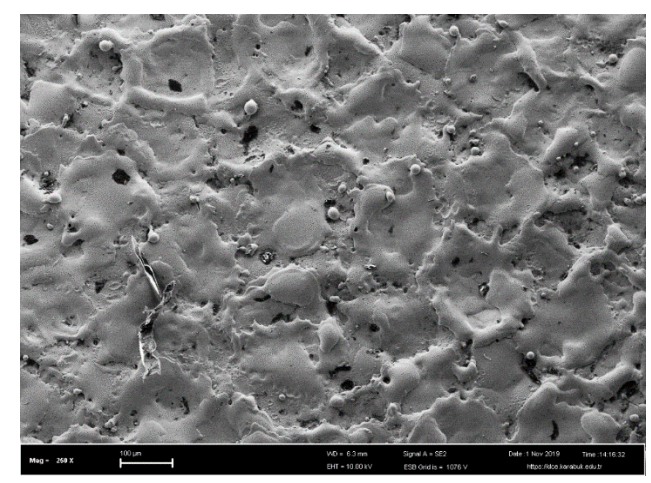

Fig. 5. SEM Micrograph at process parameters E2A1B2C2

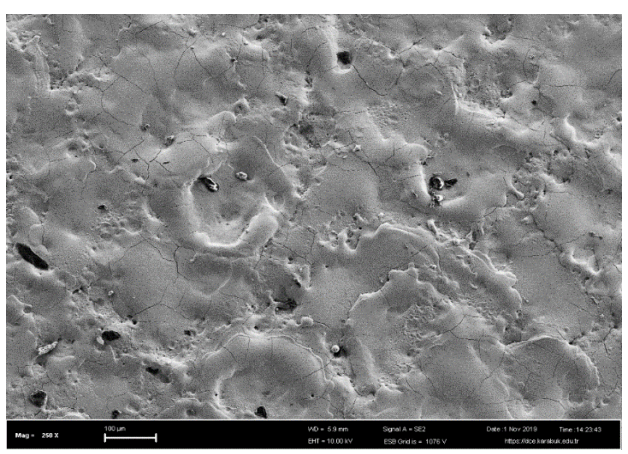

\section{Conclusion}

In the present study, the optimum set of the EDM performance parameters was determined to improve the surface finish quality. The Taguchi L18 OA and ANOVA were adopted for planning the experiments, optimizing and analyzing results. Pulse current and pulse-on time 
have the highest effect interactively on Ra yielding a wide range from 1.618 to $10.888 \mu \mathrm{m}$. The Ra sharply increased due to increase of Ip, whereas the value of $\mathrm{Ra}$ increases initially with an increase of Ton and Toff and then tends to decrease. Also it observed that a strong interaction between Ip, Ton and Toff and no interaction between electrode materials and other parameters. In addition, SEM images show the increase of SCD as a result of increase of both Ton and Toff. However, for achieving minimum surface roughness, the optimum parametric combination is $\mathrm{Ip}=6 \mathrm{~A}$, Ton $=800 \mu \mathrm{s}$, Toff $=800 \mu$ s and using B2 tool electrode.

\section{References}

Ahmad, S., \& Lajis, M. A. (2013). "Electrical discharge machining (EDM) of Inconel 718 by using copper electrode at higher peak current and pulse duration", IOP Conference Series: Materials Science and Engineering, vol. 50, pp. 1-7.

Amorim, F. L., \& Weingaertner, W. L. (2007). "The behavior of graphite and copper electrodes on the finish die-sinking electrical discharge machining (EDM) of AISI P20 tool steel", Journal of the Brazilian Society of Mechanical Sciences and Engineering, vol. 29, pp. 366-371.

Arunkumar, N., Rawoof, H. S. A., \& Vivek, R. (2012). "Investigation on the effect of process parameters for machining of EN31 ( air hardened steel ) by EDM", International Journal of Engineering, vol. 2, pp.1111-1121.

Black, J., \& Kohser, R. (2012). "Materials and processes in manufacturing" (11th ed.). John wiley \& sons, inc.

Boujelbene, M., Bayraktar, E., \& Wissem, T. (2009). "Influence of machining parameters on the surface integrity in small-hole electrical discharge machining", Archives of Materials Science and Engineering, vol. 37, pp. 110-116.

Chandramouli, S., \& Eswaraiah, K. (2018). "Experimental investigation of EDM process parameters in machining of 17-4 PH Steel using taguchi method", Materials Today: Proceedings, vol. 5, pp. 5058-5067.

Fikri, A. A., Romlie, M., \& Aminnudin, A. (2017). "Factors affecting the surface roughness in sinking EDM process", Journal of Mechanical Engineering Science and Technology, vol. 1, pp. 9-14.

Groover, M. P. (2010). "Fundamentals of modern manufacturing", Materials, Processes, and Systems, John Wiley \& Sons, Inc.

Guitrau, E. B. (1997). "The EDM handbook". Hanser Gardner Publications.

Guu, Y. H. (2005). "AFM surface imaging of AISI D2 tool steel machined by the EDM 
process", Applied Surface Science, vol. 242, pp. 245-250.

Habib, S. (2014). "Parameter optimization of electrical discharge machining process by using Taguchi approach", Journal of Engineering and Technology Research, vol. 6, pp. 27-42.

Hadad, M., Bui, L. Q., \& Nguyen, C. T. (2018). "Experimental investigation of the effects of tool initial surface roughness on the electrical discharge machining (EDM) performance", International Journal of Advanced Manufacturing Technology, vol. 95, pp. 2093-2104.

Hamid, F. E. A., \& Lajis, M. A. (2012). "High performance in EDM machining of AISI D2 hardened steel", Advanced Materials Research, vol. 500, pp. 259-265.

Ho, K. H., \& Newman, S. T. (2003). "State of the art electrical discharge machining (EDM)", International Journal of Machine Tools and Manufacture, vol. 43, pp. 1287-1300.

Jamwal, A., Vates, U., \& Aggarwal, A. (2017). "Effect of electrical and non-electrical parameters on the performance measures of electro-discharge machining a review, Indian Journal of Trend in Scientific Research, vol. 1, pp. 926-936.

Janardhanan, J., Ramnath, B., Sureshrajan, G., Siva Bharath, M., Hervin Savariraj, X., \& Akilesh, S. (2016). "Effects of die-sinking electro-discharge machining parameters on surface roughness in Inconel 825 alloy, Indian Journal of Science and Technology, vol. 9, pp. $1-5$.

Kalyon, A. (2020). "Optimization of machining parameters in sinking electrical discharge machine of caldie plastic mold tool steel", Sädhanā, vol. 45, pp. 1-13.

Krishnaiah, K., \& Shahabudeen, P. (2012). "Applied Design of Experiments and Taguchi Methods", PHI Learning Pvt. Ltd. New Delhi.

Lee, H. T., Hsu, F. C., \& Tai, T. Y. (2004). "Study of surface integrity using the small area EDM process with a copper-tungsten electrode", Materials Science and Engineering A, vol. 364, pp. 346-356.

Mahajan, A., Sidhu, S. S., \& Devgan, S. (2020). " MRR and surface morphological analysis of electrical-discharge-machined Co-Cr alloy, Emerging Materials Research, vol. 9, pp. 15 .

Patil, K. K., \& Jadhav, V. D. (2016). "Study of machining parameters in EDM". International Journal for Research in Applied Science \& Engineering Technology, vol. 4, pp. 72-78.

Sanghani, C. R., \& Acharya, G. D. (2014). "A review of research on improvement and 
optimization of performance measures for electrical discharge machining", Journal of Engineering Research and Applications, vol. 4, pp. 433-450.

Sanjeev Sharma, Rajdeep Singh, \& Sandeep Jindal. (2015). "Study the Effect of Machining Parameters in Electric Discharge Machining of EN 31 Die Steel", International Journal of Engineering Research and Technology, vol. 44, pp. 145-148.

Selvarajan, L., Manohar, M., Jayachandran, J. A. R., Mouri, P., \& Selvakumar, P. (2018). "A review on less tool wear rate and improving surface quality of conductive ceramic composites by spark EDM", Materials Today: Proceedings, vol. 5, pp. 5774-5782.

Vishwakarma, R., Yadav, S., Kumar, A., \& Krishhna, H. (2017). "Effect of different electrodes and dielectric fluids on metal removal rate and surface integrity of electric discharge machining : a Review", International Journal of Engineering Technology Science and Research, vol. 4, pp. 935-941. 